\title{
Managing Lean Principles Applicability and Implementation in the Mining Industry in Ghana. A Review Paper on Related Literature.
}

\author{
Isaac Ofori-Okyere \\ School of Business, Takoradi Technical University, Box 256, Takoradi, Ghana. \\ isaacoforiokyere@gmail.com \\ Renas Ayebono Atanga \\ School of Business, Takoradi Technical University, Box 256, Takoradi, Ghana. \\ Bernard Adjetey Okine \\ BlueFeeder Engineering Limited, Box YK1434, Kanda- Accra, Ghana.
}

\begin{abstract}
Lean manufacturing or lean production, often simply "lean", is a systematic method for the elimination of waste ("Muda") within a manufacturing system. The concept lean also comprises waste created through overburden ("Muri") and the ones created through unevenness in work loads ("Mura"). This has led to this paper review on managing Lean Principles applicability and implementation in the mining industry in Ghana. This paper reviewed both theoretical and empirical literature on lean applicability in the mining industry in Ghana. The paper seeks to explore variables, which may be considered in lean applicability and implementation in the mining industry on: principles that are identified with the lean strategies application; assess the various tools that are adopted for lean implementation; determine how the lean management strategies are applied in the mining industry; explore the main benefits derived by the players in the mining industry for adopting lean strategies; and finally, identify the challenges that confront mining companies in their quest of adopting lean strategies. It is concluded that leanness as a management principle can successfully be applied to any sector of the economy. Base on such premise (postulation), it is worth noting that there is evidence of great advances regarding leanness as a management practice in the mining industry across the globe.
\end{abstract}

Keywords: Lean applicability, lean principles, lean tools, and mining industry, Ghana.

\section{INTRODUCTION}

In the past decade, studies have been conducted into lean principles, which are applicable to the mining sector (e.g. Castillo, Alarcón and Gonzalez, 2014). Experts are of the view that these studies effectively adopt specific lean tools (principles) at a basic level as well as comprehensively, showing that this methodology is provided in the mining industry (e.g. Dunstan, Lavin and Sanford, 2006; Hattingh and Keys, 2010; Klippel, Petter and Antunes, 2008a; Shukla and Trivedi, 2012; Wijaya, Kumar and Kumar, 2009; Yingling et al., 2000). The advancement of mining has become significant a step previous to mining exploitation that offers a key contribution in the industry, signifying an enormous percentage of total costs (Castillo et al, 2014). 
Confronted with daunting challenges such as fluctuating demand, cyclical pricing and consistently experiencing reduction in the profitability within the mining sector, operating an effective and efficient business becomes crucial to any mining operation throughout the globe. That is, in spite of its inherent complexities and complications, firms in the mining sector have been incorporating lean principles into their own operations (Global Mining Magazine Apr 29, 2014), just to aim at deriving the potential benefits that come with it.

Extant studies have established the inherent differences that exist between the entire manufacturing sector and the mining industry. However, it needs to be noted that the variances are not precluding the application of leanness in the mining sector. Notably, it is held that lean principles' application cannot be attributed wholly to manufacturing industry (Dunstan et al., 2006). Notwithstanding, researchers maintain that there is a well-matched existence between the mining sector and lean, which in this case, management of any mining firm can derive benefits that comes with the application of concept such as application of value, value chain, flow, pull and perfection (Yingling et al., 2000).

The application of leanness in the mining sector, aside all other benefits, can directly lay emphases on waste application (Wijaya et al. 2009). MacDufile and Helper (1997), define waste as "anything that hinders the smooth flow of production in general. It needs to be stated that the positive examples that are linked with the use of lean principles in the mining industry, also have their attendant unique limitations, which present great challenges as well. In specifics, there are cultural aspects firmly embedded in the mining sector, which make the application of leanness as a management strategy hence facing difficulty (Freire and Alarcón, 2002).

It is reported that despite great benefits to be derived from the adoption of lean management strategies in performance improvement, other empirical studies' findings report on failures associated with the lean principles application to mean the inherent confusion regarding what and how to adopt tools in a specific environment (Tiwari, Turner and Sackett, 2007). Similarly, it is maintained that, incorrect application and implementation of lean principles can result in inefficiencies of a mining firm's resources which can also lead to reduced employee confidence in in the adoption of lean strategies (Marvel and Standridge, 2009), hence increase in waste, costs and production time of mining companies. In addition, the incorrect selection of lean strategies, may likely cause disruptions in the very processes it meant to improve. Applying and ensuring sustenance in lean principles is said not to be easy task. Some managers in the mining industry struggle with the concept and several of them have experienced failure in their attempt to apply it in their business operations. Difficulties and obstacles associated with its application emanate from a teeming number of sources and only the determination of managers allows them to be overcome and reap the rewards of successful Lean implementations (Frickle, 2010). It is in this direction that the current authors believe that it is crucial to have in place systematic method necessary and capable for implementing appropriate lean strategies based on identifying wastes in production processes as evidenced in the mining sector.

The evidence is clear that, scores of opportunities are available for mining firms to derive benefit from the adoption of lean best practice, however, it is worth stating that implementation will always not yield immediate results. The key problem under discussion and the significant research questions that need to be answered using this paper review are: Giving these backgrounds, why should the mining industry in Ghana adopt lean principles into their business processes? How can the industry apply this effectively given all the attendant potential challenges that seek to confront its application? 
There is a plethora of empirical studies conducted on lean management in different industries and environments around the globe. Bhasin (2011), identified specifically the meaning of the term, "a genuine Lean organisation" through the application of a comprehensive Lean audit focused at manufacturing firms in the UK and found out that Lean requires a considerable commitment and while successful implementation facilitates the improvement of numerous indices, the audit acquaints an organisation of the multifaceted requirements for Lean. Karim, and Arif-Uz-Zaman (2013), developed an effective methodology for implementing lean manufacturing strategies and a leanness evaluation metric using continuous performance measurement (CPM) in Australia. The findings indicated that continuous performance measurement matrices in terms of efficiency and effectiveness are proved to be appropriate methods for continuous evaluation of lean performance. Bhamu and Sangwan (2014), in India focused on the revision of LM literature and report these divergent definitions, scopes, objectives, and tools/techniques/methodologies. The authors found out that there are plethora of LM definitions with divergent objectives and scope. Theory verification through empirical and exploratory studies has been the focus of research in LM. Bateman, Hines and Davidson (2014), presented an in-depth study on the application of lean within the British Royal Air Force. The study found out that the five lean fundamental principles apply in Tornado but they need to consider specifically within the public service context particularly the pull principle. Singh, Jaiprakash and Mehta (2014), developed a statistically reliable and valid model of lean manufacturing (LM) implementation drivers for the Indian ceramic industry through an empirical study. The authors identified 12 drivers for the LM implementation in Indian ceramic industry. Lucato, Calarge, Loureiro Junior and Calado (2014), explored the implementation performance of lean principles in Brazil. The results obtained in the survey demonstrated that the performance of lean initiative implementation is not uniform among the companies located in the researched area. Outcomes also showed that the degree of implementation of the lean practices by multinational companies was higher than that for the national firms. Ljungblom (2014), researched on the practice of ethics in Swedish health care organizations using Lean Management. The findings indicated that ethics is not a consideration when hospitals are implementing Lean Management. Castillo et al. (2014), explored how to bridge the gap between the theoretical use of lean production and its practical, effective application in a Chilean mining project, and analyzed the impact of the implementation of lean construction/production methodologies in underground mining development projects. The main findings suggest that the incorporation of lean methodologies is an option, which companies should consider, given the current and future challenges in the mining business. Nadeau, Morency and Nsangou, Jr. (2015), did a contextualization of lean manufacturing in the mining sector in Canada with focus on foreseeable challenges to occupational health and safety, and summed up that recent applications of lean mining focus on the economic aspects of sustainable development.

It has become evidently clear from the foregoing discussions that the concept of lean strategies as evidence in organisations has increasing popularity due to its heavily documentation in the academic literature, and in addition to extant body of studies with findings published up to date, they all tend to focus on the American, Canadian, British, German and Swedish, Japanesse, South African markets such as the financial institutions, education, the fashion, sporting and other related fields. That is to say, unfortunately, today, there is evidence of distinct lack of empirical research conducted regarding lean applicability in the mining industry in Ghana (despite the fact that the country is been perceived as a potential market for mining products), and therefore experiencing a feedback loop for continuous performance. Hence, the justification of the current research topic. Also, in the present review, an attempt had been made by the researchers to identify the extent at which extant literature had attempted to 
determine the degree of application of leanness in the mining industry by adopting comprehensive approaches to further the investigation on the issues regarding the developing of a structured methodology of implementing and applying suitable lean strategies in the mining industry in Ghana for the purposes of evaluating the continuous performance improvement.

The general objective of this current review paper would be to contribute to and extend to existing knowledge in the area of lean principles applicability in the mining industry. The review addresses the following specific objectives: (i). to identify principles that are associated with the lean strategies and their application in the mining industry; (ii). To assess the various tools that are adopted for the lean principles implementation; (iii). To determine the types of waste evidenced in the mining industry in Ghana; (IV). To explore the main benefits derived by the players in the mining industry for adopting lean strategies; and finally, (v). To identify the challenges that confront mining companies in their quest of adopting lean strategies.

\section{LITERATURE REVIEW}

This section presents a detailed literature review on principles that are identified with the lean strategies' application; assess the various tools that are adopted for the lean implementation; determine how the lean management strategies are applied in the mining industry; explore the main benefits derived by the players in the mining industry for adopting lean strategies; and finally, identify the challenges that confront mining companies in their quest of adopting lean strategies. The section continues with the discussion of the conceptual framework, and finally comes out with conclusions to the whole review paper.'

\section{Theoretical Considerations}

\section{Definitions of Lean}

Hopp and Spearman (2004), attempted to provide a definition for lean to encapsulate the production of goods or services that takes into account minimisation of buffering costs that are linked with activities such as excess lead times, inventories, or capacity. In existing studies (e.g. Rother and Shook,1999; Abdulmaleka and Rajgopal, 2007), lean production has been defined to include identification of all types of waste found in the value stream of supply chains and implementation of tools that are essential and crucial when it comes to eliminating waste for the purpose of minimising lead times.

\section{Principles of Lean Management}

Authorities like Womack, Jones and Ross (1990), and Womack and Jones (1996), identified three core principles as they are related to lean strategy application.

1. Identifying value;

2. Eliminating waste; and

3. The generating smooth flow

These principles have been expanded by the same authorities into five more principles (Womack and Jones, 2003):

1. Identifying customer defined value.

2. Optimisation of value stream.

3. Converting the flow of value smoothly through the control and elimination of wastes.

4. Activating demand pull through synchronising customer demand and flow of information.

5. Perfecting all processes regarding products and services. 
1. Identifying customer and specific value: The foundation of this principle is purposely for identifying an exact value of the end customer in the form of specifying the most significant features of the market offering. This is because the customers of the organisation create value for it in terms of making their needs known, pricing, and timing for products or services (Karim and Arif-Uz-Zaman, 2013)." The complexity of this principle is that there might be slightly contradictory perceptions of value within different market segments.

2. Identifying and mapping the value stream: The Value Stream encompasses activities that span across every part of an organisation which involves the jointly delivery of products or services to the target customer. Value stream mapping also involves the tactical organisation of all end-to-end processes that affect the delivery of value to the target customer. With value stream mapping, all activities that are considered as nonvalue addition activities should be identified, modified removed from the entire process (Andi, Wijaya, Kumar and Kumar, 2009). The information gathered on the customer and value transformation are enough to create the value stream for the product demanded by the said customer (Karim and Arif-Uz-Zaman, 2013)."

3. Create flow through waste elimination: Create flow is considered as a value addition step that focuses on designing of processes and an establishment of capabilities that enable continuous movement throughout the process by dealing with interruption, detour or waiting through eliminating waste that is, for identifying product flow for production.

4. Pull: Pull means meeting consumer's rates of demand rather than the firm embarking on overproduction. It is suggested that no activity should be embarked on unless the outcome of it requires downstream operation. In other words, this is where the organisation's customers pull or demand products from producers through ordering for them.

5. Pursue perfection: This is considered as the final when it comes to integrating and perfecting the system so that the first four principles can be effectively and more efficiently implemented. These are the principles that seek to guide the elimination of non-value-adding elements (waste) as continuous improvement process, and the simplification of all manufacturing and support processes. It is a constant strive for improving the value specification, challenge the steps involve in value stream mapping and increase the speed connected with the flow that hidden waste can be identified and eliminated.

The five principles were later on increased by Liker (2004) to 14:

1. Base on the organisation's decisions for a long-term philosophy, even at the expense of short-term financial goals.

2. Creation of continuous process flow that is significant when it comes to bringing problems to the fore.

3. Usage of pull systems to deal with overproduction.

4. Levelling out the workload.

5. Building a culture for the organisation that has to do with putting a stop to fixing of problems but rather practising the philosophy of getting quality right first time.

6. Embarking on standardised tasks which provides a foundation for continuous improvement and empowerment for employees.

7. Usage of visual control to help detect hidden problems.

8. Usage of only dependable, thoroughly and carefully tested technology that stands to serve people in the organisation and processes put in place. 
9. Organisations should grow leaders who will strive to understand all work activities, put the philosophy into practice and to teach others.

10. Developing extraordinary individuals, teams and groups who follow the philosophy of the company.

11. Managers should respect the extension of their organisation's network of stakeholders such as suppliers and partners by challenging them and helping them to improve.

12. Managers should adopt the strategy of "go and see for yourself" (i.e. an attempt of thoroughly understanding the situation at stake).

13. Decisions must be taken slowly through consensus, with all options exhausted.

14. Managers must endeavour to grow their organisations into a learning inclined one through persistent reflection and continuous improvement.

Ljungblom (2014), maintains strongly that regardless of whether a firm is using either the five or fourteen principles, Lean Management should be treated and seen as a philosophy, and not just a set of tools and methods or procedures (techniques) as asserted by earlier authorities (e.g. Ballé and Régnier, 2007; Hines, Holweg, and Rich, 2004; Waring and Bishop, 2010; Womack and Jones, 2003).

\section{Types of Waste Evidenced In the Mining Industry}

The starting point in applying the principle of lean is by understanding the value based on customer needs. In the mining industry, especially base metal, product and customer have unique characteristics (Andi et al., 2009). Products from the mining industry are standard product that inherently has well defined specifications and requirements. Quality and price are established by global market and there is no product differentiation between firms. Transaction occurs in stock market without direct contact between mining industry as a product provider and buyer. Thus "direct" customers (companies who buy the product) do not play a role that seemed so important in the mining business. However, in a broader view, mining industry has indirect customers who are passively or actively contribute in the role of business, they are stakeholder (society, government, media, etc). Their major interest is not on quality of the product but quality behind the product, such as environment, human well-being, and economic prosperity of society. These needs are the current value of mining sector and they have been articulated in the 2009 vision of International Council on Mining and Metals (ICMM); "respected mining and metals industry that is widely recognised as essential for society and as a key contributor to sustainable development" (ICCM, 2009).

Second step in lean thinking is defining waste and its counter measure $7+1$ waste in the mining industry is described as follows:

1. Wait: Muck-pile wash or dust removal waiting period blasting is a major cause of waste creation through waiting in mining. All activities have to be stop during this period. Engineering approaches to reduce waiting time, such as better exhaust fans or duct systems, need to be investigated. Another waste associated with waiting is idle time of mobile equipment, utilisation in underground mining is low. This low utilisation is due to trade off between utilisation of mining face, utilisation of work force and utilisation of mobile equipment, where attempt is to maximise the utilisation of mining face. Cost and benefit study should be conducted to determine the optimum utilisation.

2. Over Production: Unlike automotive industry where ability of market to absorb product is fluctuating, mining industry has advantage that market is stable and it can be said that market can always absorb in spite of volume of the product. Thus, over production is not an issue in the mining industry. 
3. Repair/rework: In mining, risk involving work to repair or to rework is high due to possible and likely accident and cost related. Dynamic and unstable environment introduce constantly possibility for rework and repair that can not be avoided. However, imperfect work can be reduce by standardised procedure and method to assure the quality of work.

4. Motion: In mining, this type of waste is related on how the work is done. Currently, training for the new operator deals with mentoring system, which is done informally and non-structure. As a result, non standardised method is obtained, since variance of method between experience operators is present and trainee may perceive in the different way. Certification system is so far not applicable. Another trial for eliminating excess motion is by automation. As a requirement load is shifting from physical to cognitive, training should be designed to cover not only skill and rule based learning but also knowledge based.

5. Processing (over): Most visible form of over processing waste is the dimension of tunnel, it is common to observe that dimension of tunnel is exceeding required dimension. Causes are not solely due to the unstable rock but also due to over work in facing work. So far as scaling rock is a non standard work which is very much depending on the skill, knowledge and experience of the operator. An inexperienced operator may end up by keeping scaling of the rock, and never done, because the termination of the work is based on the subjective judgment of the operator.

6. Inventory: This type of waste is the most difficult to combat in mining. Very much higher cost of downtime compares to cost of inventory, make it a common believe that inventory is a positive. It is contrast to value of lean that inventory is root of evil. One way to tackle inventory problem is by improving reliability of equipment. It is a big challenge because majority of failure is random failure due to hostile environment. Design out Maintenance is one of the methods that can be utilised.

7. Transportation: In mining issues regarding this type of waste deals with choice of mode of transport, equipment sizing, pick up location, form of material to be transported.

8. Human Talent: This type of waste deal with under utilisation of human resource in terms of working hour and most important in terms of capacity and capability.

It is based on the belief that the human factor plays $70 \%$ when it comes to improvement potential as evidenced in the mining industry. It is advised that attention should be paid to this type of waste.

\section{Lean Tools}

In their quest of implementing leanness as a management principles in the mining sector, managers are required to note that, the principles and the tools are operating philosophy as they originated from the automotive industry, and that they are characterised with exact values, needs and features (Andi et al., 2009). The lean tools are highlighted below:

\section{$5 S$}

In Japanese language, the original five 5 S refers to Seiri, Seiton, Seiso, Seiketsu, and Shitsuke. In English, they mean to Sort, Set in order, Shine, Standardise and Sustain (Bicheno and Holweg, 2009).

Sort: All logistics or items found in the area where work activities go on are sorted orderly. First, the sorting is done to identify the needed activities and those that are not needed. The ones found not to be needed hence create waste need to to be discarded immediately. It is 
advised that when managers are in doubt, they may decide to use red colour for tagging items. A tag with red colour always has a labelling comprising a date on it and the item is left unused till the date is discarded.

In sorting, the items are grouped according to their frequency of use. Periodically, managers must do sorting, possibly once a month, and should be a regular activity and not to be treated as a re-launch of the entire tool, 5S. Also, an organisation should avoid going to the top. A few personal logistics or items should be kept in the workplace (Bicheno and Holweg, 2009). The outcomes of sorting activity can be used for the purposes of visual communication to be taking before and after photographs and have they placed on 5S board for the entire workforce to appreciate and have a full glare of the improvements (Carreira, 2004).

Set in order: As a $5 \mathrm{~S}$ tool, it explains how each item sorted can be found in the work area. In using set in order, it is advised that each item sorted must be shelved in places that will be visibly to each and every worker. There are two ways to make sure that all workers at the work area can see where each item is located, and these include colour matching of each of them with their area (labelling) and the usage of shadow boards. There is always repetition of this technique whenever there is change in any product, part, or tool (Bicheno and Holweg, 2009).

Shine: This explains that the work area must always be kept physically tidy and be done on regular basis. The workers should be tasked with the scanning of the work area for anything that is considered out of place and try to correct it immediately. A simple way of embarking on this task is taking five minutes to do repetitive clean-up exercise daily. Managers are advised to embark on these routine tasks through standardisation for the purposes of achieving best of results.

All equipment used for the cleaning and tidying up must be appropriately located and proper maintenance must be done. "Cleaning is checking' means that these are integrated. Workers need not just clean up the work area, they check for any abnormality and its root causes" (Bicheno and Holweg, 2009).

Standardise: It is advised that standards are to be developed when using the first 3Ss making sure that the entire workforce is doing what management requires of them. "Standard work aims at creating processes and procedures that are repeatable, reliable, and capable". A standard regarded as "best" is the one that is regarded by an entire workforce as also good and reliable that they would not want to do the procedure any other way (Bicheno and Holweg, 2009). Setting these standards require proper maintainance and improvement for the purpose of successful implementing of the $5 \mathrm{~S}$.

Sustain: All workers are advised to make the first four Ss a habit, and must therefore continuously endeavor to ensure their utilisation and improvement. Regular audits should be carried out to make the entire $5 \mathrm{~S}$ as principles maintained and sustained.

\section{Just-in-time (JIT)}

Just-in-Time is a lean technique that lays emphasis on the continuous process when it comes to waste elimination and productivity improvement within the work area. Ohno (1988), perceived that for Just-in-time to work effectively, each business process of the firm should be giving right parts needed at the right time and in the right amount or quantity needed to produce an order from a customer to ensure the highest quality. Just-in-time as an important lean concept was adopted by TPS which allowed the automobile company to eliminate all forms of waste ranging from work-in-process inventory, flaws (defects), and poor delivery of 
parts (Nahmias, 1997). Considered as a critical tool, JIT is used for the management of business activities which include distribution and purchasing, and are categorised into three: just-intime production, just-in-time distribution and just-in-time purchasing. The main goal for JIT's usage is to "produce and transport just what is needed, just when it is needed, in just the amount needed, within the shortest possible lead time" (Drew, McCullum and Roggenhofer, 2004), and this can be related to the concept of having raw materials delivered, at the time needed and manufactured products also supplied at the time needed" (Lai, 2009).

\section{Kaizen}

Kaizen is considered as one of the most recognised words in the Japanese Language. In dividing the words into two parts, "Kai" means continuous and "zen" is translated as improvement. Kaizen hinges on the assumption that no business process can be seen as perfect hence more for improvement always. Hence, there must be "continuous improvement, in small increments, at all levels [of the company], forever". Kaizen is regarded as critical for the implementation of scores of lean techniques hence continuous improvement aftermath. Most of kaizen events address internal processes of a firm, and are also applicable in any part of the supply chain (Trent, 2008) process.

\section{Kanban}

"Kanban is considered as a classic signalling device (mechanism) for production pull systems" (Bicheno and Holweg, 2009). There are two types of kanbans; that is single and dual card kanban. The most popular one among the two which is used in lean management systems is the "single card" kanban. A single card kanban (also known as a pull signal) is used between pairs of work stations. A product kanban, considered as a kind of single card kanban, operates as whenever a product vis-à-vis a container is taken out, it is replaced with another. In the absence of a pull out that means authorisation has not been given and therefore production has put on hold (Bicheno and Holweg 2009).

It was the Toyota Company established the Dual card kanban to deal with the usage of two main kanban cards that is, the production kanban card (also known as supplier process) and the conveyance kanban card (also known as customer process). At this stage, supplier process is defined as the various processes a supplier goes through in an attempt to have parts replenished, while the customer process deals with all the processes that involves converting raw materials to finished products (in the form of assembly) (syque quality 2005). A Kanban is not tangible card. It can be designed in an electronic square plastic kanban card or a kanban container. A kanban square also known as kaban rectangle is always painted on the floor of the factory and it serves as a signal when it comes to replenishing an empty container.

\section{Improvement Cycles}

As lean management tool, improvement cycles provide the framework to ensure a continuous process for improvement. It needs to be stressed that having an approach which is standardised and is aimed at continuous improvement is always regarded as a great value for all firms. Improvement Cycles are divided into two variations namely; PDCA and IDEA

\section{Plan Do Check Act (PDCA)}

PDCA is recognised as extensively used improvement cycle around the globe. As a type of improvement cycle, PDCA requires the organisation to embark on massive planning. The planning aspect of adopting PDCA deals with creating a hypothesis with the end customers and putting their requirements in mind, hence the organisation customer focus. It is advised that the organisation must adopt continuous communication and dialogue in developing a 
hypothesis that predicts an expected result. Bicheno and Holweg (2009) is of the view that a time plan needs to be developed.

After planning, the next activity comes doing. Doing in actual sense means implementation of improvement plan at this stage. The last activity refers to checking and as the name suggests, managers must check if the activity done was as predicted /or planned (Bicheno and Holweg, 2009). Once the checking activity is complete, the organisation can then put the results of checking into work. All the necessary changes or modifications are made giving way to the creation of standards. As the cycle begins once again, the end result standards are continuously improved upon. A large deviation gives an indication that something went wrong (Bicheno and Holweg, 2009) from the beginning.

\section{Investigate Design Execute Adjust (IDEA)}

Authorities on the adoption of lean tools regard IDEA similar to PDCA. It is used by the Toyota Company for innovation and design (Bicheno and Holweg, 2009) purposes. A company begins this cycle by investigating anything that calls for investigation such as an identified problem, customers' concern, data and the rest. After investigating, management presents the findings. New solutions are then implemented and subsequently giving adjustment to prepare for the next cycle and bring it close to the firm's requirements (Bicheno and Holweg, 2009).

\section{Value Stream Mapping}

As regarded as lean tool, managers adopt Value Stream Mapping to aim at visual improvement that deals with the creation of maps to show the "Current State, Future State, Ideal State, and Action Plan" of a company. It is advised that the entire process involving mapping must lead to an action otherwise it will be considered as not adding to value, hence waste. The core objective of adopting value stream mapping is make the identification of various non value added activities after which management puts processes in place to eliminate them.

\section{Benefits Derived From the Implementation and Applicability of Lean as a Management Strategy}

It has become a norm for most manufacturing firms to continually strive in their quests of increasing productivity and output regarding their operations for the main purposes of satisfying their customers (Tinoco, 2004), who are considered as the most important personalities to their businesses (Ofori-Okyere, 2014), by serving them right product, right quality, right quantity, and the right price in shortest possible of time.

An aspect of lean manufacturing is mainly for reviewing business operations for production operational components, processes or materials that add cost rather than value (Tapping, 2002). To achieve efficiency, it is advised that each step involving the process in manufacturing should be monitored as a way for determining if it adds value to the product or creates waste. If a non-value added element is detected, that part of the process could be outsourced to a subcontractor in order for the company to focus on the staff in achieving value-added operations in its core business.

Lean manufacturing is always adopted by value oriented firms for the purposes of identifying and eliminating wastes associated with processes of production. Companies are advised to use these results to help map their future state and to ensure successful implementation of lean in manufacturing processes (Tinoco, 2004).

The lean production implementation has greater and wider scope when it comes to enhancing productivity, customer satisfaction and achieving profits (Apleberger, Jonsson and Ahman, 
2007) both short and long term. The goal of adopting lean management or in the mining sector seeks to the elimination of activities in the work area that are considered as non-value additions which include waiting, repair or rework, motion, over-processing, inventory, transportation (Dunstan et al., 2006), and that is, reducing costs (Wijaya, et al., 2009, Sanda, Johansson, and Johansson, 2011; Sanda, 2012; Liu, 2013) or extracting ore faster (Wei-Jian and Qian, 2010). Womack and Jones (2003), perceived lean management as aiming at a continuous improvement of an organisation's value creation capability by engaging all employees.

Adopting this philosophy throughout a firm is supposed to be positively correlated with higher efficiency (Dahlgaard and Dahlgaard-Park, 2006). Lean manufacturing is regarded as a strategy in business operations used in achieving the shortest possible cycle time when it comes to waste elimination (Liker, 1997).

Other benefits derived from adopting lean manufacturing usually promises of lower costs, higher quality, and shorter lead times (Liker, 1997). Lean as a manufacturing term is applied to achieve less human effort by the firms, less manufacturing space, less investment in tools, less inventory in progress, and less engineering hours to develop a new product in less time (Paranitharan, Begam, Abuthakeer and Subha, 2011), while giving customers what they demand in a highly economical manner.

The concept of Lean has been praised for empowering employees (Hasle, 2014), and it lays emphasizes on waste reduction and on maximising or fully utilising activities that contribute to adding value from the perspective of the customer (Ohno, 1988; Womack et al., 1990). In practice, the term waste specifically implies, any activity that absorbs resources and creates no value (Chauhan and Singh, 2012) to the organisation's operations. Leanness in manufacturing is considered a concept that seeks to unify the various practices involve in the promotion of lean as a management philosophy (Womack et al., 1990)

LM applicability provides manufacturers with competitive edge by achieving reduction in cost and improve productivity and quality. Many authorities have documented quantitative benefits derived from adopting lean implementation such as improving production lead time, processing time, cycle time, set up time, inventory, defects and scrap, and overall equipment effectiveness. On the qualitative benefits derived by companies for adopting LM, they are said to include improved employee morale, effective communication, job satisfaction, standardized housekeeping, team decision making, etc. (Bhamu and Sangwan, 2014).

Lean as a management concept is adopted for the purposes of optimising usage of resources available when there is the need to minimise waste (Anand and Kodali, 2009), and the creation of high quality goods and services at a lowest possible cost with maximum customer responsiveness (Kumar, Singh, Qadri, Kumar and Haleem, 2013). It is instructive and fair to posit that, initiatives that emanate from business improvement programmes involving the adoption of lean strategies which include minimised shutdowns, increased production and increased chances of reaching annual targets.

In general, lean manufacturing philosophy requires respect from management towards the people(the workers), aims at continuous improvement, a long-term view, a level of patience, a focus on process and ability to understand where the individual is in his or her development (Ahmad, 2013). Lastly, under the lean concept, all non-value adding activities are regarded as waste generators that divert resources from the value adding activities of the organisation. 


\section{Challenges Associated With the Adoption of Lean Management or Lean Manufacturing}

Despite the potential benefits derived from the application of leanness as a management principle in business processes of mining firms, the challenges bedeviling its adoption deserve serious consideration. Some theorists both in the academia and industry have shown a greater interest regarding potential challenges associated with the adoption of lean strategies as managerial tool. The success of any particular strategy in management is always said to be dependent upon organisational characteristics, which implies that all firms cannot implement or apply a similar set of strategies in their particular case (Shah and Ward, 2003).

Lean principles are not just adapting the tool but how to change the culture, 'a true culture of continuous improvement'. In contrast to innovation approach which emphasize on a quick improvement/change, lean principle is a continuous improvement approach which emphasize on a small but constantly improves. In implementing lean thinking in the mining sector, managers should understand that leanness in manufacturing is an operating philosophy in its original context (automotive industry) that had particular values, needs and characteristics. Mining operations are characterized as dynamic, uncertain, volatile and risky work environment.

The application of unsuitable lean technique for a given situation can sometimes lead to increase in waste, cost and production time in a manufacturing company like mining. Due to inappropriate implementation of lean strategies, there may be changes that are likely to create disruptions in the process it is meant to improve continuously. It is in this wise that the application of lean concept in the mining firms becomes crucial and critical for managers to have in place systematic method capable of implementing appropriately a strategy based on the identification of wastes as evidence in manufacturing processes.

In the main, it can be stressed that there are important barriers in other words known as challenges confronting organizations in their quests of implementing lean strategies. Some of these challenges are: culture of the organisation, poor flexibility, employees resisting change and innovation, etc. (Achanga, Shehab, Roy, and Nelder, 2005; Nordin, Deros and Wahab, 2010; Zhou, 2012), high workforce turnover (Andi et al., 2009), which is advised that much effort should be emphasized on training for new workers recruited by the mining company. The applicability of lean philosophy in the mining sector seemed complicated, given the issue of uncertainties and variability characterising activities in mining (Nadeau et al., 2015).

In addition to the challenges, specific mention can be made to lack of clear customer focus (Hines et al., 2004; Radnor and Walley, 2008; Radnor et al., 2012), that is, in the context of mining industry it is challenging for the term customer to be clearly defined within the operational context of the mining firms. The mining industry like any other industry is sometimes saddled with too many procedures and targets considered major barrier (Radnor and Walley, 2008; Waring and Bishop, 2010). There is clear evidence of lack of understanding regarding the lean system thinking and process flow (Ballé and Régnier, 2007; Dahlgaard et al., 2011; Emiliani, 1998; Radnor and Walley, 2008; Radnor et al., 2012; Waring and Bishop, 2010), on the part of managers of lean thinking and their subordinates.

There is also lack of awareness regarding strategic direction (Hines et al., 2004; Radnor and Walley, 2008; Waring and Bishop, 2010) for the organisation's quests of applying lean philosophy. Another barrier confronting the implementation and applicability of Lean in the mining industry is the firm's inability to reconstruct the massive impact of historical top-down change approaches into Lean's bottom-up improvement methodology (Emiliani, 1998; Hayward, 2012) or to find a combination of the two (Anhede and Lord, 2009). 
The implementation and applicability of the Lean concept in the mining industry requires development of leaders who can function effectively as motivators, coaches and be able to grow and develop persons and teams (Anhede and Lord, 2009; Poksinska et al., 2013) as in transformational leadership (Ljungblom, 2012; Poksinska et al., 2013), a distinct and high quality of leadership is necessary to get through the change (Joosten et al., 2009; Kimsey, 2010; Poksinska et al., 2013; Waring and Bishop, 2010). Studies reveal how Lean managers has changed the focus of managerial work - from managing operations to managing people (Poksinska et al., 2013).

Managers must always endeavour to understand the process involving the applicability and implementation of lean and the needed respect giving to the people along the way (Kimsey, 2010). Nonetheless, managers who regard Lean as more than a set of tools and techniques makes it a barrier in terms of its understanding. Also, attempting to develop a culture that initiates the involvement of everyone in the organisation is critical to the implementation and applicability of the Lean philosophy - the daunting task is everyone needs to be trained (Ballé and Régnier, 2007; Dahlgaard et al., 2011; Emiliani, 1998; Hines et al., 2004; Radnor Walley, 2008; Radnor et al., 2012; Waring and Bishop, 2010; Womack and Jones, 2003). All these barriers need to be mitigated for lean manufacturing successful adoption and diffusion in the mining sector. Identifying accurate drivers is capable of helping in taking effective lean decisions during lean implementation planning process.

Conceptual Framework

LEAN APPLICABILITY IN THE MINING SECTOR

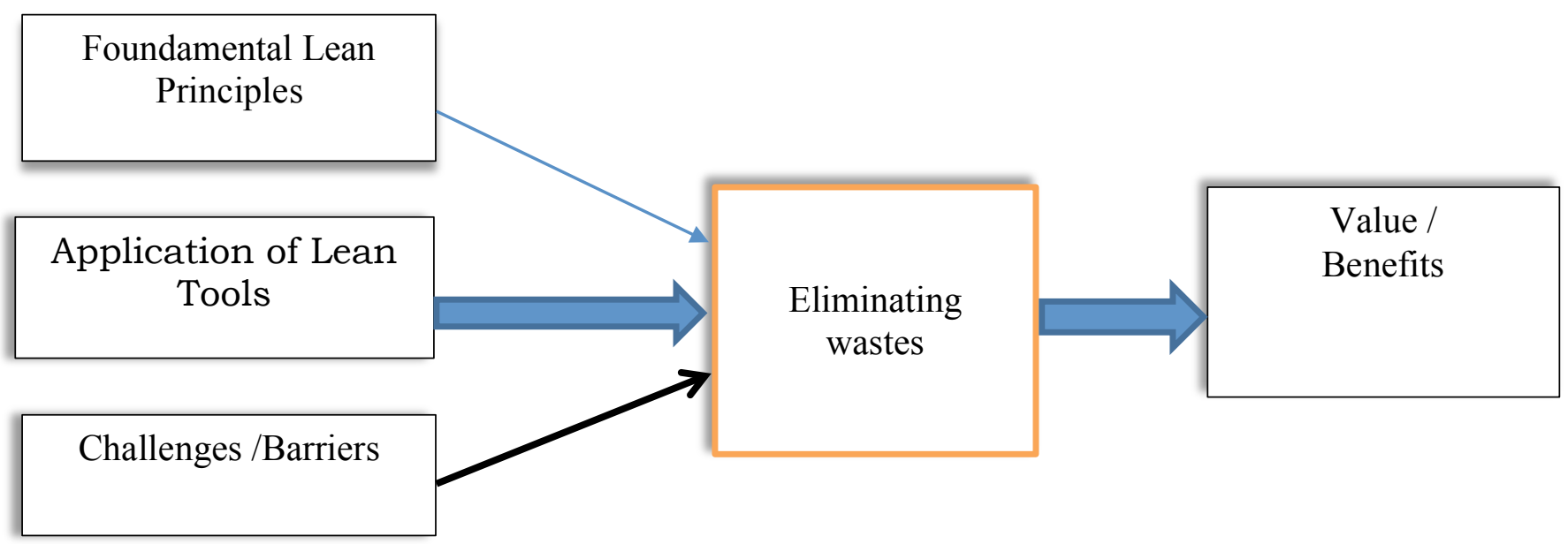

Based on the theories from (Womack et al. 1990; Womack and Jones, 1996; Womack and Jones, 2003; Bicheno \& Holweg, 2009).

Figure 1, above presents a detailed illustration regarding conceptual framework of this related literature review. Improper and ineffective application or implementation of lean strategies can lead to inefficiencies in a mining firm's resources hence increasing waste in diverse forms, cost and production time. However, it can be hold as a firm truth that proper applicability of the lean strategies (involving the principles), and effective selection of right lean tools are significant in eliminating all forms of wastes that occasioned in business operations of any organization hence achieving value by the organization and to providing value that is associated with the products and services offered to stakeholder groups. The existence of wastes in organisations bring to the fore visible challenges that contribute to confront 
manufacturing organisations in their quests of applying or implementing lean strategies. So it can be maintained that total elimination of wastes as evidenced in an organisation's business operations is a proof that the management have been able to deal with challenges that confront them in their quests of successfully applying Lean strategies.

\section{CONCLUSION}

It has been postulated that leanness as management principle can successfully be applied to any sector of the economy. Base on such proposition or premise (postulation), it is worthy of mention that there is evidence of great advances regarding leanness as a management practice in the mining industry around the globe. Panoply of empirical studies have reported the significant role played by applicability of lean thinking in the business operations of the mining companies (e.g. Karlsson and Ahlstrom, 1996; Humphreys, 2001; Collard, Noort, and Seal, 2007; Klippel, Petter, and Antunes Jr., 2008a; Andi et al., 2009; Castillo et al., 2014; Nadeau et al., 2015). For the purpose of this literature search, it has been established that during lean implementation, emphasises should be laid on customer value. Also, equally important and worth noting is that (Bicheno \& Holweg, 2009), Leannes in the mining sector is "behaviourdriven"; that is managers ensuring its implementation and sustenance must be abreast with its continuous process and should be driven at making it so. In order to expand the understanding of lean applicability or implementation in the mining industry; this literature search has developed a lean applicability framework and has evaluated the impact of it in mining exploitation projects undertaken by the players in the industry. Adapting lean management philosophy in the mining sector is just a beginning. Although the concept promises gains in productivity, its implementation in the mining sector is complicated, given the uncertainties and variability characterising mining activities.

\section{ACKNOWLEDGEMENT}

The current researchers duly acknowledge and extend their sincere gratitude to all the scores of authorities whose existing works were obtained and cited in this work of review.

\section{References}

1. Abdulmaleka, F.A. and Rajgopal, J. (2007). "Analyzing the benefits of lean manufacturing andvalue stream mapping via simulation: a process sector case study”, Int. J. Prod. Economics, Vol. 107, pp. 223-36.

2. Achanga, P., Shehab, E., Roy, R. and Nelder, G. (2005). "Critical success factors for lean implementation within SMEs”, Journal of Manufacturing Technology Management, Vol. 17 No. 4, pp. 460-471.

3. Ahmad, S.A.S. (2013). "Culture and lean manufacturing: towards a holistic framework", Australian Journal of Basic and Applied Sciences, Vol. 7 No. 1, pp. 334-338.

4. Anhede, P. and Lord, M. (2009). "Att implementera lean - en generell beskrivning och ett exempel från Universitetssjukhuset i Lund", Chefer and ledare, No. 2, pp. 4-13, available at: www.skane.se/Public/SUS_extern/Om_oss/Lean/Dokument/Att_implementera_lean.pdf (accessed 28 January 2013).

5. Anand, G. and Kodali, R. (2009). "Simulation model for the design of lean manufacturing systems - a case study", International Journal of Productivity and Quality Management, Vol. 4 No. 5, pp. 691-714.

6. Andi, R., Wijaya, R., Kumar, R., and Kumar, R. (2009). Implementing Lean Principle into Mining Industry Issues and Challenges. International Symposium on Mine Planning and Equipment Selection nov.16, Banff Kanada.

7. Apleberger, L., Jonsson, R., Åhman, P., 2007. Byggandets industrialisering: Nulägesbeskrivning, Göteborg: Sveriges Byggindustrier.

8. Ballé, M. and Régnier, A. (2007). "Lean as a learning system in a hospital ward”, Leadership inHealth Services, Vol. 20 No. 1, pp. 33-41. 
9. Bateman, N., Hines, P., Davidson, P. (2014). "Wider applications for Lean ", International Journal of Productivityand Performance Management, Vol. 63 Iss 5 pp. 550 - 568

10. Bhasin, S. (2011)."Measuring the Leanness of an organisation", International Journal of Lean Six Sigma, Vol. 2 Iss 1 pp. $55-74$.

11. Bhamu, J. and Sangwan, K.S. (2014)."Lean manufacturing: literature review and research issues", International Journal of Operations \& Production Management, Vol. 34 Iss 7 pp. 876 - 940

12. Bicheno, J. and Holweg, M. (2009). The Lean Toolbox: The essential guide to lean transformation. 4th edition. Buckingham: PICSIE Books

13. Carreira, B. (2004). Lean Manufacturing That Works: Powerful Tools for Dramatically Reducing Waste and Maximizing Profit. New York: AMACOM Books

14. Castillo, G, Luis F. Alarcón, L.F. and Vicente A. Gonzalez, V.A. (2014). Proceedings IGLC-22, June 2014 | Oslo, Norway

15. Chauhan, G. and Singh, T.P. (2012). "Measuring parameters of lean manufacturing realization", Measuring Business Excellence, Vol. 16 Iss 3 pp. 57 - 71.

16. Collard, M., Noort, D., and Seal, W., (2007). The Lean Mining Network 'Connecting Lean Mind', the Association for Manufacturing Excellence (AME) Conference 2007, Chicago, USA.

17. Dahlgaard, J., Pettersen, J. and Dahlgaard-Park, S. (2011), "Quality and lean healthcare: a system for assessing and improving the health of healthcare organizations", Total Quality Management, Vol. 22 No. 6, pp. 673-689.

18. Dahlgaard, J.J. and Dahlgaard-Park, S.-M. (2006). "Lean production, six sigma quality, TQM and company culture”, The TQM Magazine, Vol. 18 No. 3, pp. 263-281.

19. Drew, J., McCallum, B. \& Roggenhofer, S. (2004). Journey to Lean Making Operational Change Stick Palgrave Macmillan Houndmills, Basingstoke, Hampshire RG21 6XS and 175 Fifth Avenue,New York, N.Y. 10010

20. Dunstan, K., Lavin, B. and Sanford, R. (2006).The Application of Lean Manufacturing in a Mining Environment. International Mine Management Conference, Melbourne, Vic, October 16-18, 144-157.

21. Emiliani, M.L. (1998). “Lean behaviors”, Management Decision, Vol. 36 No. 9, pp. 615-631.

22. Emiliani, M.L. (2005). “Using kaizen to improve graduate business school degree programs”, Quality Assurance in Education, Vol. 13 No. 1, pp. 37-52

23. Global Mining Magazine Apr 29, (2014). How to Implement Lean Principles in the Mining Industry.

24. Freire, J., and Alarcón, L. F. (2002). Achieving lean design process: Improvement methodology. Journal of Construction Engineering and Management, 128(3), 248-256.

25. Fricke, C.F. (2010). Lean Management: Awareness, Implementation Status, and need for Implementation Support in Virginia's Wood Industry. Virginia Polytechnic Institute and State University Master of Science Thesis.

26. Hasle, P. (2014). "Lean production - an evaluation of the possibilities for an employee supportive lean practice", Human Factors and Ergonomics in Manufacturing and Service Industries, Vol. 24 No. 1, pp. 4053.

27. Hattingh, T., and Keys, O. (2010). How applicable is industrial engineering in mining? Platinum in Transition 'Boom Or Bust', 4th International Platinum Conference, Sun City, South Africa. 205-210.

28. Hayward, L.M. (2012). "How applicable is lean in mental health? A critical appraisal", The International Journal of Clinical Leadership, Vol. 17 No. 3, pp. 165-173.

29. Hines, P., Holweg, M. and Rich, N. (2004). "Learning to evolve: a review of contemporary lean thinking", International Journal of Operations \& Production Management, Vol. 24 No. 10, pp. 994-1011.

30. Hopp, W.J. and Spearman, M.L. (2004). “To pull or not to pull: what is the question?" Manufacturing \& Service Operations Management, Vol. 6 No. 2, pp. 133-48. 
31. Humphreys, D., (2001). Sustainable Development: can the mining industry afford it?, Resources Policy, 27.

32. International Council on Mining and Metals 2009 vision.

33. Joosten, T., Bongers, I. and Janssen, R. (2009). “Application of Lean thinking to health care: issues and observations”, International Journal for Quality in Health Care, Vol. 21 No. 5, pp. 341-347.

34. Karim, A. and Arif-Uz-Zaman, K. (2013)."A methodology for effective implementation of lean strategies and its performance evaluation in manufacturing organizations", Business Process Management Journal, Vol. 19 Iss 1 pp. 169 - 196.

35. Karlsson C. and Ahlstrom P., (1996). Assessing changes towards lean production, International Journal of Production Management, 16, 2.

36. Klippel, A., Petter, C., and Antunes Jr., J. (2008a). Lean management implementation in mining industries. DYNA, 75(154), 81-89.

37. Klippel, A. F., Petter, C. O., and Antunes Jr., J. A. V. (2008b). Management innovation, a way for mining companies to survive in a globalized world. Utilities Policy, 16(4), 332-333.

38. Kimsey, D. (2010). "Lean methodology in health care”, AORN Journal, Vol. 92 No. 1, pp. 53-60.

39. Kumar S., Singh B, Qadri Md. Asim, Kumar Y.V. Satya and Haleem Abid, (2013). "A framework for comparative evaluation of lean performance of firms using fuzzy TOPSIS", Int. J. Productivity and Quality Management, Vol. 11, No. 4, 2013.

40. Lai, K, C. (2009). Just-in-Time Logistics. Oxon: Ashgate Publishing Group

41. Liker, J. (1997). Becoming lean: Inside stories of U. S. manufacturers. Portland, OR: Productivity Press.

42. Liker, J. K., (2004). The Toyota Way: 14 Management Principles from the World's Greatest Manufacturer, Mc Graw-Hill.

43. Liu, Z. (2013). Study on Coal Lean Mining Theory and Practice. Advanced Materials Research, 605-607, 538-541.

44. Ljungblom, M. (2012).“A comparative study between developmental leadership and Lean leadership similarities and differencies", Management and Production Engineering Review, Vol. 3 No. 4, pp. 45-68.

45. Ljungblom, M. (2014)."Ethics and Lean Management - a paradox?", International Journal of Quality and Service Sciences, Vol. 6 Iss 2/3 pp. $191-202$.

46. Lucato, W.C., Calarge, F.A., Mauro Loureiro Junior, M. and Calado, R.D. (2014)."Performance evaluation of lean manufacturing implementation in Brazil", International Journal of Productivity and Performance Management, Vol. 63 Iss 5 pp. 529 - 549

47. MacDufile, J.P. and Helper, S. (1997). “Creating lean suppliers: diffusing lean production through the supply chain", paper presented at International Motor Vehicle Program (IMVP), FY'97 IMVP working papers.

48. Marvel, J.H. and Standridge, C.R. (2009). “A simulation-enhanced lean design process”, Journal of Industrial Engineering \& Management, Vol. 2 No. 1, pp. 90-113.

49. Nadeau, S., Morency, F., and Nsangou, J.R. Jr. (2015). The contextualization of lean manufacturing in the mining sector: foreseeable challenges to occupational health and safety. Proceedings 19th Triennial Congress of the IEA, Melbourne 9-14 August 2015

50. Nahmias, S. (1997). Production and Operations Analysis, Irwin, Chicago, IL.

51. Nordin, N., M. d Deros, B. and Abd Wahab, D. (2010). “A survey on lean manufacturing implementation in Malaysian automotive industry", International Journal of Innovation, Management and Technology, Vol. 1 No. 4, pp. 374-380.

52. Ofori-Okyere, I. (2014). Customer Communications -Theories, approaches and Frameworks. DingleFoot Publishing Company. Kumasi, Ghana.

53. Ohno, T. (1988).Toyota Production System. Beyond Large-Scale Production, Productivity Press, Cambridge, MA. 
54. Paranitharan, K.P., Begam, M.S., Abuthakeer, S.S. and Subha, M.V. (2011). “Redesigning an automotive assembly line through lean strategy", International Journal of Lean Thinking, Vol. 2 No. 2, pp. 1-14.

55. Poksinska, B., Swartling, D., Drotz, E., (2013). The daily work of Lean leaders- lessons from manufacturing and healthcare. Total Qual. Manag. Bus. Excell. 1-13.

56. Radnor, Z. and Walley, P. (2008). "Learning to walk before we try to run: adapting Lean for the public sector", Public Money and Management, Vol. 28 No. 1, pp. 13-20.

57. Radnor, Z.J., Holweg, M. and Waring, J. (2012). “Lean in healthcare: the unfilled promise?”, Social Science and Medicine, Vol. 74 No. 3, pp. 364-371.

58. Rother, M. and Shook, J. (1999). Learning to See - Value Stream Mapping to Create Value and Eliminate Muda, Version 1.2, The Lean Enterprise Institute Brookline, Brookline, MA, available at: www.lean.org

59. Sanda, A. (2012). Procedural Knowledge and Declarative Learning as Macroergonomic Resources for Enhancing Lean Mining Sustainability. International Journal of Contemporary Business Studies, 3 (9), 2745.

60. Sanda, M.A., Johansson, J. and Johansson, B. (2011). Miners' Tacit Knowledge: A Unique Resource for Developing Human-oriented Lean Mining Culture in Deep Mines. Proceedings of the 2011 IEEE IEEM, 399-404.

61. Shah, R. and Ward, P.T. (2003). "Lean manufacturing: context, practice bundles, and performance", Journal of Operations Management, vol. 21, no. 2, pp. 129-149.

62. Shukla, R., and Trivedi, M. (2012). Productivity improvement in coal mining industry by using lean manufacturing. International Journal of Emerging Trends in Engineering and Development, 6, 580-587.

63. Singh, K., Jaiprakash, S., and Mehta, B.D. (2014). "Development of lean manufacturing implementation drivers for Indian ceramic industry", International Journal of Productivity and Performance Management, Vol. 63 Iss 5 pp. $569-587$.

64. Singh, B., Garg, S.K, and Sharma, S.K. (2010). "Development of index for measuring leanness: study of an Indian auto component industry", Measuring Business Excellence, Vol. 14 Iss 2 pp. 46 - 53.

65. Syque quality. (2005). Further Kanban. Accessed 26th March 2013. http://www.syque.com/quality_tools/tools/Tools61.htm

66. Tapping, D., Luyster, T., \& Shuker, T. (2002). Value stream management: Eight steps to planning, mapping, and sustaining lean improvements. New York, NY: Productivity Press.

67. Tinoco, J.C. (2004). Implementation of Lean Manufacturing. University of Wisconsin-Stout MSC. Thesis.

68. Tiwari, A., Turner, C. and Sackett, P. (2007). "A framework for implementing cost and quality practices within manufacturing", Journal of Manufacturing Technology Management, Vol. 18, pp. 731-60.

69. Trent, R.J. (2008). End-to-end lean management: a guide to complete supply chain improvement, Ft. Lauderdale, FL: J. Ross Pub, Ft. Lauderdale, FL.

70. Waring, J.J. and Bishop, S. (2010). "Lean healthcare: rhetoric, ritual and resistance", Social Science and Medicine, Vol. 71 No. 7, pp. 1332-1340

71. Wei-Jian, Y. and Qian, G. (2010). Optimization Design of Deep Lean-ore mining and Safety Evaluation. Journal of Coal Science \& Engineering, 16(2), 163-169

72. Wijaya, A.R., Kumar, R., and Kumar, U. (2009). Implementing Lean Principle into Mining Industry Issues and Challenges. International Symposium on Mine Planning and Equipment Selection, November 16-19, Banff, Canada, 1-9.

73. Womack, J., Jones, D., and Ross, D. (1990). The machine that changed the world: Based on the Massachusetts institute of technology 5-million-dollar 5-year study on the future of the automobile. New York: Rawson Associates.

74. Womack, J.P. and Jones, D.T. (1996). Lean Thinking, Touchstones Books, London. 
75. Womack, J.P. and Jones, D.T. (2003). Lean Thinking. Banish Waste and Create Wealth in Your Corporation, Free Press, New York, NY.

76. Trent, R.J. (2008). End-to-end lean management: a guide to complete supply chain improvement, $\mathrm{Ft}$. Lauderdale, FL: J. Ross Pub, Ft. Lauderdale, FL.

77. Yingling, J. C., Detty, R. B., and Sottile Jr., J. (2000). Lean manufacturing principles and their applicability to the mining industry. Mineral Resources Engineering, 9(2), 215-238.

78. Zhou, B. (2012). "Lean principles, practices, and impacts: a study on small and medium-sized enterprises (SMEs)", Annals of Operations Research, pp. 1-18, doi: 10.1007/s10479-012-1177-3. 